\title{
Bio-relevant Dissolution Media Development
}

\section{Sharma MK*}

Department of Analytical Research and Development, Amneal Pharmaceuticals LLC, Brookhaven, NY, USA

Generic pharmaceutical industry is a most important part of health care system, which provides affordable care to Americans. Generic drugs are same in strength, administration route, dosage form, safety and efficacy as brand drugs. The only thing in which generic drugs are not same as brand drugs is cost, in fact the generic pharmaceutical association states that consumers who are able to replace all their brand name drugs with generics can save up to $30 \%$ to as much as $80 \%$ on their daily drug costs [1]. Generic drugs are cheaper than brand drugs because it does not require multi stage clinical trials and lengthy formulation development. Generic drug must be bioequivalent with brand drug (should have same amount of absorption in blood as brand drug). Several unsuccessful bio studies may increase the cost of drug development and in the case of first to file status filling, ANDA (Abbreviated New Drug Application) applicant may lose the race. Development of bioequivalent formulation is a vary clanging task for formulator and being an analytical scientist it is our responsibility to develop a dissolution media which can show correlation between in vitro and in vivo release profile of generic and brand drug.

Dissolution test is essential for all solid oral doses form and it is used in all phases of development for product release and stability testing. In the case of lipophilic drugs dissolution release can be rate-limiting step in the in vivo absorption process and hence the dissolution medium is a critical component of the test that can cause problems [2,3]. The most challenging step is to correlating in vitro drug release to in vivo drug profile (IVIVC). Food effect on drug release and bioavailability of drug can be predicted by Bio relevant dissolution testing. In vitro dissolution in Bio relevant media simulates conditions of GI tract. Based upon food affect bio relevant dissolution media separated into two categories i.e., Fasted state and Fed state. Dr. Jennifer Dressman has developed Biorelevant gastrointestinal media that simulate the fasted and fed state [4].

The preparation procedure for the Bio-relevant media is mention [4].

Fasted State Simulated Intestinal Fluid (FaSSIF) (Table 1).

\section{Preparation of blank FaSSIF}

Dissolve $1.74 \mathrm{~g}$ of sodium hydroxide pellets, $19.77 \mathrm{~g}$ of sodium dihydrogen phosphate monohydrate or $17.19 \mathrm{~g}$ of sodium dihydrogen phosphate anhydrous and $30.93 \mathrm{~g}$ of sodium chloride in $5 \mathrm{~L}$ of purified water. Adjust the $\mathrm{pH}$ to exactly $\mathrm{pH} 6.5$ using $1 \mathrm{~N}$ Sodium hydroxide solution or $1 \mathrm{~N}$ Hydrochloric acid solution.

\section{Preparation of FaSSIF}

Dissolve 3.3 g sodium taurocholate was dissolved in approximately $500 \mathrm{~mL}$ of the blank FaSSIF. Then $11.8 \mathrm{~mL}$ of a Methylene chloride solution containing $100 \mathrm{mg} / \mathrm{mL}$ lecithin was added. This produced an emulsion (i.e., the resulting product was turbid). The Methylene chloride was then evaporated under vacuum using a Rotavap at a temperature of about $40^{\circ} \mathrm{C}$. About $10 \mathrm{~min}$ at $500 \mathrm{mbar}$ followed by $30 \mathrm{~min}$ at about $50 \mathrm{mbar}$ led to complete removal of the methylene chloride. The result was a clear, micellar solution having no perceptible odor of Methylene chloride. After cooling to room temperature, the volume was brought to $2 \mathrm{~L}$ with blank FaSSIF.

Fed State Simulated Intestinal Fluid (FeSSIF) (Table 2).

\section{Preparation of blank FeSSIF}

Dissolve $20.2 \mathrm{~g}$ of sodium hydroxide pellets, $43.25 \mathrm{~g}$ of glacial acetic acid and $59.37 \mathrm{~g}$ of sodium chloride in $5 \mathrm{~L}$ of purified water. Adjust the $\mathrm{pH}$ to exactly $\mathrm{pH} 5.0$ using $1 \mathrm{~N}$ Sodium hydroxide solution or $1 \mathrm{~N}$ Hydrochloric acid solution.

\section{Preparation of FeSSIF}

Dissolve $16.5 \mathrm{~g}$ of sodium taurocholate in $500 \mathrm{~mL}$ of blank FeSSIF. Add $59.08 \mathrm{~mL}$ of a solution containing $100 \mathrm{mg} / \mathrm{mL}$ lecithin in methylene chloride, forming an emulsion. The methylene chloride is eliminated under vacuum at about $40^{\circ} \mathrm{C}$. Draw a vacuum for fifteen minutes at $250 \mathrm{mbar}$, followed by $15 \mathrm{~min}$ at $100 \mathrm{mbar}$. This results in a clear to slightly hazy, micellar solution having no perceptible odor of methylene chloride. After cooling to room temperature, adjust the volume to $2 \mathrm{~L}$ with blank FeSSIF.

The recommended volume for simulating conditions in the upper small intestine after a meal is $1 \mathrm{~L}$.

In pharmaceutical industries Dr. Dressman bio-relevant media is widely used but this media also has some limitation and cannot

\begin{tabular}{|c|c|}
\hline Reagents & Quantity \\
\hline Sodium taurocholate $(\mu \mathrm{M})$ & $3 \mathrm{mM}$ \\
\hline Lecithin $(\mu \mathrm{M})$ & $0.75 \mathrm{mM}$ \\
\hline Sodium Hydroxide (Pellets) & $0.174 \mathrm{~g}$ \\
\hline Sodium dihydrogenphosphate monohydrate & $1.977 \mathrm{~g}$ \\
\hline Sodium Chloride & $3.093 \mathrm{~g}$ \\
\hline Water & $500 \mathrm{~mL}$ \\
\hline Media has a pH of 6.50 and an osmolality of about 270 mOsmol $/ \mathrm{kg}$. \\
\hline
\end{tabular}

Table 1: Composition of fasted-state simulated gastric fluid (FaSSIF).

\begin{tabular}{|c|c|}
\hline Reagents & Quantity \\
\hline Sodium taurocholate $(\mu \mathrm{M})$ & $15 \mathrm{mM}$ \\
\hline Lecithin $(\mu \mathrm{M})$ & $3.75 \mathrm{mM}$ \\
\hline Sodium Hydroxide (Pellets) & $4.04 \mathrm{~g}$ \\
\hline Glacial acetic acid & $8.65 \mathrm{~g}$ \\
\hline Sodium Chloride & $11.874 \mathrm{~g}$ \\
\hline Water & $1000 \mathrm{~mL}$ \\
\hline Media has a pH of 5.00 and an osmolality of about $6700 \mathrm{mOsmol} / \mathrm{kg}$. \\
\hline
\end{tabular}

Table 2: Composition of fed state simulated intestinal fluid (FaSSIF).

*Corresponding author: Manish Kumar Sharma, Department of Analytical Research and Development, Amneal Pharmaceuticals LLC, Brookhaven, NY, USA, Tel: +1-732-789-0035; E-mail: mannsharma06@gmail.com

Received January 20, 2017; Accepted January 23, 2017; Published January 30 , 2017

Citation: Sharma MK (2017) Bio-relevant Dissolution Media Development. J Bioequiv Availab 9: e74. doi:10.4172/jbb.10000e74

Copyright: (c) 2017 Sharma MK. This is an open-access article distributed under the terms of the Creative Commons Attribution License, which permits unrestricted use, distribution, and reproduction in any medium, provided the original author and source are credited. 
show in vivo-in vitro correlation (IVIVC) for all class of drugs. Drugs, which has very limited solubility and needed higher concentration of surfactant to dissolve, will not show IVIVC in Dr. Dressman's biorelevant media. In that case analytical scientist should develop biorelevant dissolution media and conditions by considering following,

1. Location of drug released from drug product.

2. Total time to release drug completely from drug product.

3. Chemical composition of fluids in which drug is released.

Another approach to develop a bio-relevant dissolution media also widely used by generic industry in the case of first unsuccessful bioequivalence study. This procedure is called reverse bio-relevancy. In this dissolution development scientist develops media and parameters for failed pilot/pivotal batch and brand batch which was used in clinical dosing and target to match bioequivalence study (in vivo) data. Finalized condition can be applied on further development batches, which will help formulator to decide next bioequivalence study batch.
The development of bio-relevant dissolution media is very important in generic pharmaceutical industry. Developing bio-relevant dissolution media not only provide information on drug behaviour in human body but also helps formulation scientist to early stage developments and later stage modification of formulation.

\section{References}

1. http://www.gphaonline.org/about/generic-medicines/

2. Gander B, Ventouras K, Gurny R, Doelkar E (1985) In vitro dissolution medium with supramicellar surfactant concentration and its relevance for in vivo absorption. Int J Pharm 27: 117-124.

3. Lehto P (2010) Mechanistic studies of Drug Dissolution testing: Implications of solid phase properties and in vivo prognostic media. Academic dissertation, Division of Pharmaceutical Technology Faculty of pharmacy, University of Helsinki Mechanistic, Finland, pp: 1-49.

4. Dressman JB, Reppas C (2000) In vitro-in vivo correlations for lipophilic, poorly water-soluble drugs. Eur J Pharmaceut Sci 93: 91-100. 